\title{
Core Competencies of Clinical Research Coordinators
}

\author{
Izumi Kohara $^{1 *}$, Akiko Nosaki ${ }^{2}$, Noriko Morishita ${ }^{3}$, Nobuko Ushirozawa ${ }^{4}$, \\ Kazushi Endo ${ }^{5}$, Hiroshi Yamada ${ }^{6}$, Takao Taniguchi ${ }^{7}$ and Hideo Kusuoka ${ }^{8}$ \\ ${ }^{1}$ School of Nursing, Jichi Medical University \\ ${ }^{2}$ Graduate School of Nursing, Chiba University \\ ${ }^{3}$ National Hospital Organization Osaka National Hospital \\ ${ }^{4}$ National Cancer Center \\ ${ }^{5}$ Japanese Society of Hospital Pharmacists \\ ${ }^{6}$ School of Pharmaceutical Sciences, University of Shizuoka \\ ${ }^{7}$ Japan Association of Site Management Organization (JASMO) \\ ${ }^{8}$ National Hospital Organization \\ *Corresponding author, E-mai:ikohara@jichi.ac.jp
}

\begin{abstract}
A standardized education program covering core competencies of clinical research coordinators (CRCs) is necessary to match the sophisticated and expanding role of CRCs. This study focused on identifying core competencies of CRCs in order to develop a standard education program. Data from presentations given by thirteen experts were first analyzed by the text mining approach. Categories extracted by software of text mining were then edited, summarized and identified based on the property of the data. The following twelve elements were extracted as core competencies of CRCs: rational problem-solving, management, communication, coordination, being knowledgeable, caring for research subjects, working as a team, consultation, ensuring the quality of clinical researches, behavior as a medical personnel, leadership, and information technology (IT) skill. Those core competencies are essential abilities of CRCs working in a clinical setting with research subjects. Management might be a central competency. Further research is needed to clarify the scopes of practice and performance level of CRCs in order to develop an education program that focuses on the core competencies of CRCs.
\end{abstract}

Keywords: Clinical Research Coordinator, Core Competency, Education

\section{Introduction}

Clinical research coordinators (CRCs) are professionals who work at a clinical research site with study subjects under the immediate direction of a principal investigator, whose research activities are conducted under Good Clinical Practice (GCP) guidelines [1]. There is a critical need for training CRCs. The reasons are: 1) protocols have become progressively more complex, and regulations intended to protect the safety of research subjects and study data integrity have continued to evolve; 2) as a result, the CRC's role has become more sophisticated and the CRC's responsibilities have expanded even though training programs do not cover these new responsibilities of CRCs; and 3) the additional responsibilities of CRCs place increasing burdens that could adversely affect their primary role of research subject management [2]. However, several articles suggested that only approximately half of CRCs had opportunities of training [2-3]. A warning letter by the US FDA also suggested inadequate training of CRCs [4]. The Clinical and Translational Science Award Research Coordinator Taskforce of the US National Institutes of Health recommended that institutions conduct a gap analysis of their training program focusing on the core competencies of CRCs [2]. 
Competency is more than just knowledge and skills; it involves the ability to meet complex demands by drawing on and mobilizing psychosocial resources (including skills and attitudes) in a particular context [5]. Core competencies specifically refer to a group of skills or procedures that an individual must be able to successfully and competently perform [6]. The importance of competency has been emphasized in many areas of health care [6].

However, there are no described core competencies of CRCs. The Oncology Nursing Society provides Clinical Trials Nurse Competencies [7] for nurses in the oncology field. Approximately 30-40\% of CRCs have a nursing license [2], indicating that $60-70 \%$ of CRCs have a license in another field or no license. Therefore, it is necessary to describe the core competencies that apply to all CRCs regardless of licensure. The fourteen contents of the typical role of CRCs shown by the Association of Clinical Research Professionals (ACRP) [8] do not describe the essential abilities of CRCs to meet the complex demands of their role. Although the Joint Task Force (JTF) for Clinical Trial Competency showed that the core competencies consist of eight domains [9], that study focused on the competencies of clinical research professionals (CRPs) including not only CRCs but also clinical research associates (CRAs) such as data managers, project managers, monitors and auditing persons. Therefore, core competencies that focus on the abilities or skills required by CRCs who work at a clinical research site with study subjects have not been identified. Those core competencies of CRPs emphasized the actual activities included in each competency domain, and it is difficult to understand the essential characteristics of CRCs.

Revealing the core competencies of CRCs would provide helpful information to develop a standard education program that matches the sophisticated and expanding role of CRCs. This study focused on determining the core competencies of CRCs. In this study, core competencies of CRCs were defined as essential abilities that CRCs require including knowledge, skills and attitudes.

\section{Methods}

This was an exploratory study using the text mining approach.

\subsection{Study Participants}

The criteria for selecting participants were a person who has stated an opinion regarding the role expectation and education of CRCs and is acknowledged as an opinion leader in Japan by the investigators. The investigators used convenience sampling [10] to select study participants using networks in the research community in Japan.

\subsection{Data Collection}

The primary investigator informed each participant about the purpose of the study and asked the participant to prepare an oral presentation of 15 minutes in length about what is expected of CRCs. Participants were invited to investigator's meetings for this study and freely presented his/her opinion about what is expected of CRCs from August 2013 to August 2014. We invited two participants to the first meeting to hear their opinions in August 2013. To collect other opinions after summarizing the data from the first meeting, we invited five participants to the second meeting in October 2013, and invited six participants to the third meeting in August 2014. The investigators heard the views of the participants regarding what is expected of CRCs. We concluded that data saturation was achieved after the third meeting; therefore, we did not add more participants.

The investigators had the opportunity to ask questions to the participants after their presentations. Although we did not prepare any guide for the questions, we asked them questions and had discussions with them until the meanings of each participant's opinion became clear. The meetings were audiotaped and transcribed verbatim. 


\subsection{Data Analysis}

Data from the audiotaped meetings were analyzed using the text mining approach. Text mining seeks to extract useful information from data sources through the identification and exploration of interesting patterns [11]. We first mined text from verbatim records of the meetings by using the software of text mining, IBM ${ }^{\circledR}$ SPSS ${ }^{\circledR}$ Text Analytics for Surveys 4.0.1 including the Japanese language. We then edited categories extracted by that software, grouped them into large categories, and identified the core competencies of CRCs while not using that software. Table 1 shows the process of data analysis.

The detailed process of analysis was as follows. (1) Text mining: The resource template of that software read verbatim records on a one-sentence basis. By that reading, verbatim records on a one-sentence basis were separated to parts of speech: noun, verb, adjective and adverb (excluding personal names, geographical names, and organization names). The separated parts of speech were extracted from the records and categorized based on the linguistic approach of that software, and categories were developed. (2) Editing: We checked all parts of speech that were not extracted by that software. Parts of speech describing CRCs' core competencies were picked up according to the definition of core competency of CRCs and were included in existing categories or placed in new categories. Some names of categories that were automatically made by the text data mining software did not appropriately show the property of the parts of speech included in that category. Therefore, we checked all names of the categories and modified them if necessary. As a result, there were 62 categories. (3) Summarizing: The categories were manually grouped into large categories. Twelve large categories as candidates of core competencies of CRCs were extracted. (4) Identifying: The validities of the large categories were identified among the investigators. Finally, twelve core competencies of CRCs were revealed.

IK analyzed all processes, and AN confirmed their validity.

Table 1. Process of Data Analysis

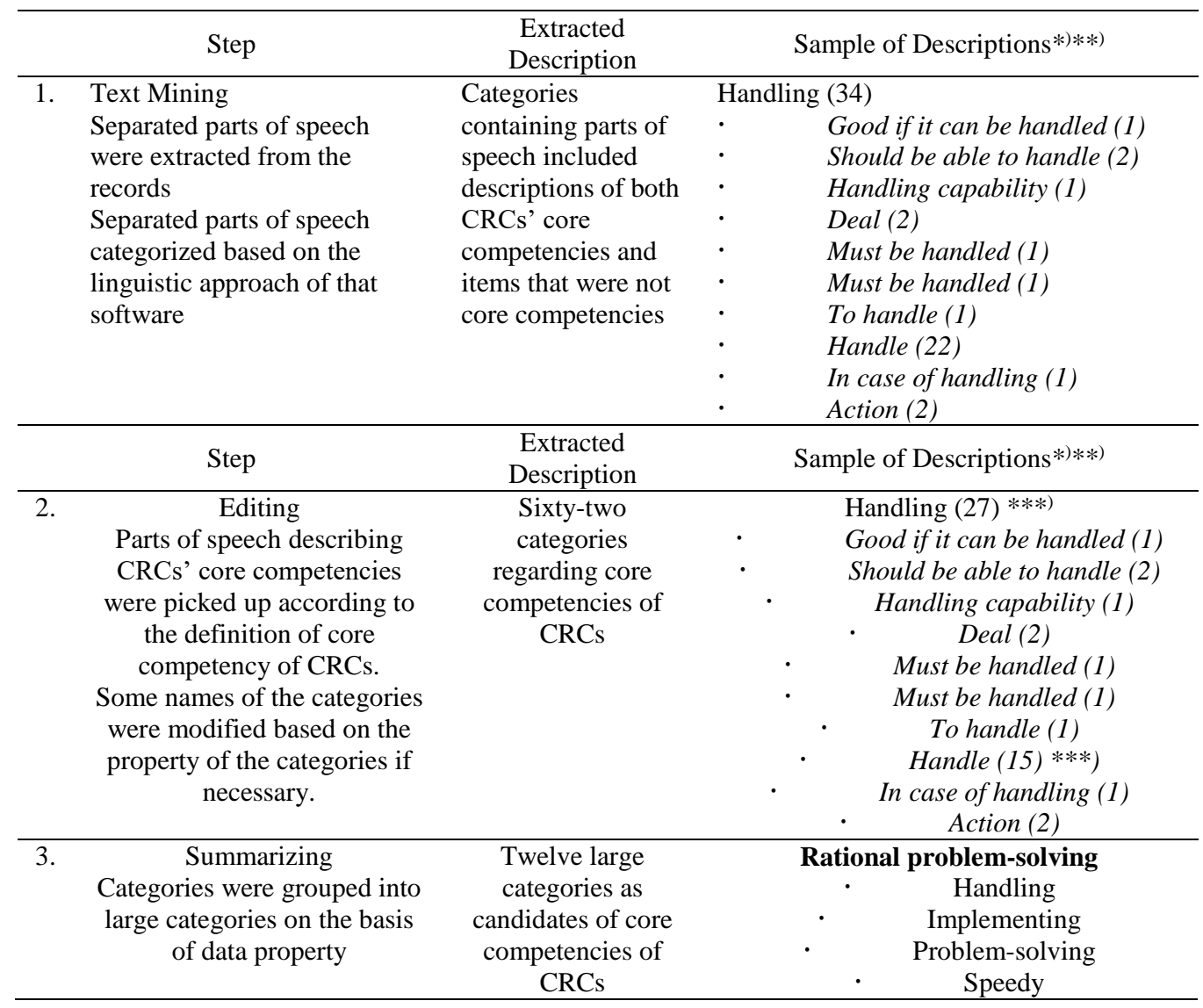




\begin{tabular}{|c|c|c|c|}
\hline & & & 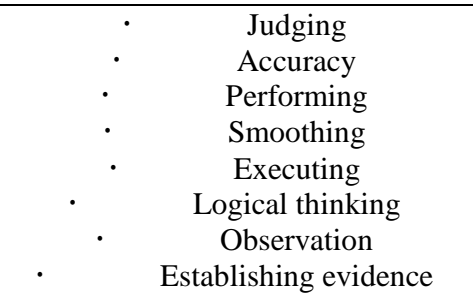 \\
\hline 4. & $\begin{array}{c}\text { Identifying } \\
\text { Validities of the large } \\
\text { categories were identified } \\
\text { among the investigators }\end{array}$ & $\begin{array}{c}\text { Twelve core } \\
\text { competencies of } \\
\text { CRCs }\end{array}$ & $\begin{array}{c}\text { - Rational problem-solving } \\
\text { - Management } \\
\text { - Communication } \\
\text { - Coordination } \\
\text { - Being knowledgeable } \\
\text { - Caring for research subjects } \\
\text { - Working as a team } \\
\text { - Consultation } \\
\text { - Ensuring the quality of clinical } \\
\text { researches } \\
\text { - Behavior as a medical personnel } \\
\text { - Leadership } \\
\text { - Information technology (IT) skill }\end{array}$ \\
\hline
\end{tabular}

*Parts of speech are indicated in italic; large categories are indicated in bold

**The number in parentheses indicates the number of records.

***This number is smaller than that in Step1 because it is the number that was remaining after parts of speech describing CRCs' core competencies were picked out.

\section{Results}

We recruited 13 opinion leaders who consisted of a patient advocate, principal investigators, clinical research professionals and education professionals in health care. Table 2 shows the background of the participants.

Table 2. Background of the Participants $(\mathrm{N}=13)$

\begin{tabular}{ll}
\hline Background & $\mathrm{N}$ \\
\hline $\begin{array}{l}\text { Clinical research associate who had experience as a clinical research } \\
\text { coordinator }\end{array}$ & 1 \\
$\begin{array}{l}\text { Manager of clinical research organization } \\
\text { Manager of pharmaceutical company }\end{array}$ & 1 \\
$\begin{array}{l}\text { Manager of the Academic Research Organization (ARO) who had experience } \\
\text { as a clinical research coordinator }\end{array}$ & 1 \\
$\begin{array}{l}\text { Manager who provides a learning program of clinical research funded by the } \\
\text { Ministry of Health, Labor and Welfare }\end{array}$ & 1 \\
$\begin{array}{l}\text { Medical journalist } \\
\text { Patient advocate }\end{array}$ & 1 \\
$\begin{array}{l}\text { President of university who was involved in the initiative of clinical research } \\
\text { coordinators training program }\end{array}$ & 1 \\
$\begin{array}{l}\text { Clinical research coordinator who had experience as a trainer } \\
\text { Physician / Principal Investigator }\end{array}$ & 1 \\
\hline
\end{tabular}

After analyzing the audiotaped meetings, the total number of records was 517. Sixtytwo categories were extracted from 426 records $(82.4 \%)$. The 62 categories were placed in 12 large categories as core competencies of CRCs (Table 3). The 12 large categories of core competencies of CRCs were as follows.

The first large category was "Rational problem-solving", which had 12 categories such as handling, implementing, problem-solving and others from 85 records (16.4\%). The second large category was "Management", which had 9 categories such as management, 
project management, risk management and so on from 66 records $(12.8 \%)$. The third large category was "Communication", which had 9 categories such as communication, negotiation, explainable and so on from 54 records (10.4\%). The fourth large category was "Coordination", which had 5 categories such as navigation, coordination, flexibility and so on from 53 records (10.2\%).The fifth large category was "Being knowledgeable", which had 3 categories of knowledge, understanding and well-understanding from 34 records $(6.6 \%)$. The sixth large category was "Caring for research subjects", which had 6 categories such as understanding patients, care, ethical action and so on from 32 records $(6.2 \%)$. The seventh large category was "Working as a team", which had 6 categories such as working with others, being independent, asking and so on from 26 records (5.0\%).

The eighth large category was "Consultation", which had 3 categories of supporting, advising, and easy to consult from 25 records (4.8\%). The ninth large category was "Ensuring the quality of clinical researches", which had 4 categories of ensuring quality, protocol compliance, monitoring and auditing from 23 records (4.4\%). The tenth large category was "Behavior as medical personnel", which had two categories of medical personnel and fairness from 13 records $(2.5 \%)$. The eleventh large category was "Leadership", which had 2 categories of leadership and activating from 12 records $(2.3 \%)$. The twelfth large category was "Information Technology (IT) skill", which had 1 category from 3 records $(0.6 \%)$.

\section{Table 3. Core Competencies of CRCs Identified in this Study Number of all Records $=\mathbf{5 1 7}$}

\begin{tabular}{|c|c|c|c|}
\hline $\begin{array}{c}\text { Large } \\
\text { Categories }\end{array}$ & Categories & $\begin{array}{l}\text { Number of } \\
\text { records }(\%)\end{array}$ & Including parts of speech \\
\hline \multirow[t]{12}{*}{$\begin{array}{l}\text { Rational } \\
\text { problem-solving }\end{array}$} & Handling & $27(5.2)$ & $\begin{array}{l}\text { Good if it can be handled, should be able to handle, } \\
\text { handling capability, deal, must be handled, must be } \\
\text { handled, to handle, handle, in case of handling, } \\
\text { action }\end{array}$ \\
\hline & Implementing & $13(2.5)$ & Feasibility, implementation, implementing \\
\hline & Problem-solving & $9(1.7)$ & $\begin{array}{l}\text { Problem, solution, solving, problem-solving skill, } \\
\text { ability to solve problems, problem solving }\end{array}$ \\
\hline & Speedy & $8(1.5)$ & Speed, speedy, input speed \\
\hline & Judging & $8(1.5)$ & To judge, judgment, ability to judge information \\
\hline & Accuracy & $5(1.0)$ & $\begin{array}{l}\text { Accuracy, conscientious, information processing } \\
\text { ability, person who are particular about the details, } \\
\text { attention to details, meticulous person }\end{array}$ \\
\hline & Performing & $5(1.0)$ & $\begin{array}{l}\text { To accomplish, to complete, completing, ability to } \\
\text { perform jobs }\end{array}$ \\
\hline & Smoothing & $3(0.6)$ & Smooth, smoothness \\
\hline & Executing & $2(0.4)$ & Ability to execute, practical skills \\
\hline & Logical thinking & $2(0.4)$ & Logical, ability to think \\
\hline & Observation & $1(0.2)$ & Observation skill \\
\hline & $\begin{array}{l}\text { Establishing } \\
\text { evidence }\end{array}$ & $2(0.4)$ & Evidence, establishing evidence \\
\hline \multirow[t]{4}{*}{ Management } & Management & $17(3.3)$ & $\begin{array}{l}\text { Management, managing person, management } \\
\text { ability, resource, self-check, ability to manage, } \\
\text { management, shared management, research and } \\
\text { development management, under management }\end{array}$ \\
\hline & $\begin{array}{l}\text { Project } \\
\text { management }\end{array}$ & $13(2.5)$ & Project management, project, project manager \\
\hline & $\begin{array}{l}\text { Risk } \\
\text { management }\end{array}$ & $12(2.3)$ & $\begin{array}{l}\text { Risk-based, risk evaluation, brake, risk-based } \\
\text { monitoring, repeating, danger, risk, risk assessment }\end{array}$ \\
\hline & $\begin{array}{l}\text { Data } \\
\text { management }\end{array}$ & $8(1.5)$ & $\begin{array}{l}\text { Input, managing data, electronic data capture, case } \\
\text { report form、 data management }\end{array}$ \\
\hline
\end{tabular}




\begin{tabular}{|c|c|c|c|}
\hline & $\begin{array}{l}\text { Time } \\
\text { management }\end{array}$ & $7(1.4)$ & Time, time management \\
\hline & $\begin{array}{l}\text { Schedule } \\
\text { management }\end{array}$ & $4(0.8)$ & $\begin{array}{l}\text { Being able to manage a schedule, schedule } \\
\text { management, schedule }\end{array}$ \\
\hline & $\begin{array}{l}\text { Original source } \\
\text { management }\end{array}$ & $3(0.6)$ & Original source, medical chart \\
\hline & $\begin{array}{l}\text { Document } \\
\text { management }\end{array}$ & $1(0.2)$ & Required documentation \\
\hline & Making systems & $1(0.2)$ & Being organized \\
\hline \multirow[t]{9}{*}{ Communication } & Communication & $17(3.3)$ & $\begin{array}{l}\text { Ability to communicate, communication ability, } \\
\text { communication, communication skills, two-way } \\
\text { communication }\end{array}$ \\
\hline & Negotiation & $6(1.2)$ & Negotiation, ability to negotiate \\
\hline & Explainable & $5(1.0)$ & $\begin{array}{l}\text { Providing information, a person able to explain, } \\
\text { explanation }\end{array}$ \\
\hline & $\begin{array}{l}\text { Asserting own } \\
\text { opinion }\end{array}$ & $4(0.8)$ & Opinion, express an opinion \\
\hline & Partnership & $3(0.6)$ & Partner each other, equal partners, parallel \\
\hline & $\begin{array}{l}\text { Creating } \\
\text { relationships }\end{array}$ & $4(0.8)$ & Trust, trusting relationship, relationship \\
\hline & $\begin{array}{l}\text { Business } \\
\text { manner }\end{array}$ & $3(0.6)$ & Business manner \\
\hline & $\begin{array}{l}\text { English } \\
\text { proficiency }\end{array}$ & $9(1.7)$ & English language ability, letter in English, English \\
\hline & Medical writing & $3(0.6)$ & $\begin{array}{l}\text { Person able to support SAE report creation, medical } \\
\text { writing }\end{array}$ \\
\hline $\begin{array}{c}\text { Large } \\
\text { Categories } \\
\end{array}$ & Categories & $\begin{array}{l}\text { Number of } \\
\text { records }(\%)\end{array}$ & Including parts of speech \\
\hline \multirow[t]{5}{*}{ Coordination } & Navigation & $17(3.3)$ & $\begin{array}{l}\text { Person able to guide, to navigate, guidance, } \\
\text { navigate, navigator }\end{array}$ \\
\hline & Coordination & $15(2.9)$ & $\begin{array}{l}\text { Ability to coordinate, coordination, concerning the } \\
\text { department, receptor, coordination ability, } \\
\text { coordinate, relevant parties, would like to have } \\
\text { coordinated, ability to coordinate }\end{array}$ \\
\hline & Flexibility & $9(1.7)$ & $\begin{array}{l}\text { Flexible, flexibility, pliant, withdrawal, suiting to } \\
\text { the occasion }\end{array}$ \\
\hline & $\begin{array}{l}\text { Sharing } \\
\text { information }\end{array}$ & $7(1.4)$ & To share, information, sharing \\
\hline & $\begin{array}{l}\text { Sense of } \\
\text { balance }\end{array}$ & $5(1.0)$ & Sense of balance, balanced, balance \\
\hline \multirow[t]{3}{*}{$\begin{array}{l}\text { Being } \\
\text { Knowledgeable }\end{array}$} & Knowledge & $17(3.3)$ & $\begin{array}{l}\text { Basic knowledge, knowledgeable, technical } \\
\text { knowledge, being knowledgeable, knowledge }\end{array}$ \\
\hline & Understanding & $15(2.9)$ & To understand, able to understand \\
\hline & $\begin{array}{l}\text { Well } \\
\text { understanding }\end{array}$ & $2(0.4)$ & Person able to understand, essence \\
\hline \multirow[t]{6}{*}{$\begin{array}{l}\text { Caring for } \\
\text { research } \\
\text { subjects }\end{array}$} & $\begin{array}{l}\text { Understanding } \\
\text { patients }\end{array}$ & $12(2.3)$ & $\begin{array}{l}\text { Things understood, was able to understand, not } \\
\text { having knowledge, understanding better } \\
\text { comparatively, was not able to understand, to not } \\
\text { understanding }\end{array}$ \\
\hline & Care & $6(1.2)$ & $\begin{array}{l}\text { Relevant person, person who was gave care, } \\
\text { confrontation, consideration, care, kind, to } \\
\text { accompany, making arrangements }\end{array}$ \\
\hline & Ethical action & $5(1.0)$ & $\begin{array}{l}\text { Ethical, would like to be treated with honesty, sense } \\
\text { of ethics }\end{array}$ \\
\hline & $\begin{array}{l}\text { Making patients } \\
\text { a priority }\end{array}$ & $4(0.8)$ & Patient-centered \\
\hline & $\begin{array}{l}\text { Respecting } \\
\text { participant }\end{array}$ & $3(0.6)$ & $\begin{array}{l}\text { For the sake of participants, protection of } \\
\text { participants }\end{array}$ \\
\hline & $\begin{array}{l}\text { Advocate for a } \\
\text { patient }\end{array}$ & $2(0.4)$ & Advocate for a patient \\
\hline
\end{tabular}




\begin{tabular}{|c|c|c|c|}
\hline \multirow[t]{6}{*}{$\begin{array}{l}\text { Working as a } \\
\text { team }\end{array}$} & $\begin{array}{l}\text { Working with } \\
\text { others }\end{array}$ & 10(1.9) & $\begin{array}{l}\text { Cooperation, collaboration, being team work, } \\
\text { cooperating }\end{array}$ \\
\hline & $\begin{array}{l}\text { Being } \\
\text { Independent }\end{array}$ & $6(1.2)$ & Oneself, independent person \\
\hline & Asking & $4(0.8)$ & Asking \\
\hline & $\begin{array}{l}\text { Contacting/Infor } \\
\text { ming }\end{array}$ & $2(0.4)$ & Contacting, informing \\
\hline & Responsibility & $2(0.4)$ & Sense of responsibility, responsibility \\
\hline & Cooperative & $2(0.4)$ & Cooperativeness, cooperative \\
\hline \multirow[t]{3}{*}{ Consultation } & Supporting & $14(2.7)$ & $\begin{array}{l}\text { Support, clinical research professionals, will } \\
\text { support, virtually supporting, support }\end{array}$ \\
\hline & Advising & $7(1.4)$ & $\begin{array}{l}\text { Educational, continuing to communicate, advice, } \\
\text { instruction, supervise, continuing to educate }\end{array}$ \\
\hline & Easy to consult & $4(0.8)$ & $\begin{array}{l}\text { Would like to consult, place for consultation, } \\
\text { consultation service }\end{array}$ \\
\hline \multirow{4}{*}{$\begin{array}{l}\text { Ensuring the } \\
\text { quality of } \\
\text { clinical } \\
\text { researches }\end{array}$} & Ensuring quality & $9(1.7)$ & $\begin{array}{l}\text { Guarantee, based upon GCP, quality, compliance, } \\
\text { condition, scientific evidence }\end{array}$ \\
\hline & $\begin{array}{l}\text { Protocol } \\
\text { compliance }\end{array}$ & $9(1.7)$ & $\begin{array}{l}\text { Deviation, conforming to protocol, protocol } \\
\text { management, conforming to protocol, without } \\
\text { deviation }\end{array}$ \\
\hline & Monitoring & $3(0.6)$ & Able to monitor \\
\hline & Auditing & $2(0.4)$ & Audit, person able to audit \\
\hline \multirow{2}{*}{$\begin{array}{l}\text { Behavior as a } \\
\text { medical } \\
\text { personnel }\end{array}$} & $\begin{array}{l}\text { Medical } \\
\text { personnel }\end{array}$ & $9(1.7)$ & $\begin{array}{l}\text { Medical profession, in order to become a medical } \\
\text { practitioner, medical personnel }\end{array}$ \\
\hline & Fairness & $4(0.8)$ & conflict of interest, fairness \\
\hline $\begin{array}{c}\text { Large } \\
\text { Categories } \\
\end{array}$ & Categories & $\begin{array}{l}\text { Number of } \\
\text { records }(\%)\end{array}$ & Including parts of speech \\
\hline \multirow[b]{2}{*}{ Leadership } & Leadership & $8(1.5)$ & Leadership, to lead \\
\hline & Activating & $4(0.8)$ & $\begin{array}{l}\text { Activate, system promoting research, for research } \\
\text { activities, activating }\end{array}$ \\
\hline $\begin{array}{l}\text { Information } \\
\text { Technology (IT) } \\
\text { skill }\end{array}$ & IT skill & $3(0.6)$ & PC skills \\
\hline
\end{tabular}

\section{Discussion}

The responsibilities of CRCs, role of CRCs and content of training programs for CRCs have already been reported [2, 8]. However, previous studies did not show the core competencies that CRCs need. The present study clarifies core competencies of CRCs that had been extracted from oral presentations from 13 opinion leaders.

This study identified more essential abilities of CRCs working in a clinical setting with research subjects than those found in a previous study on the competencies of CRPs [9]. Caring for research subjects, ensuring the quality of clinical researches, and behavior as a medical personnel are competencies reflecting the practical responsibilities of CRCs in clinical settings. CRCs serve a pivotal role in human subject protection [2], which is described as the competency of caring for research subjects. Protocol compliance, monitoring, and auditing are included in the large category "Ensuring the quality of clinical researches" in our results. CRCs are expected to be the leading person in clinical settings to ensure compliance with GCP guidelines and contribute to the reliability of the research study. Behavior as a medical personnel is a prerequisite competency for CRCs to perform those roles. The roles of CRCs are different from those of CRAs who don't provide direct care for research subjects and directly don't handle the data source. It is significant that our study revealed the core competencies of CRCs separately from those of CRPs including CRAs [9].

Other core competencies identified in this study warrant further discussion. Management, one of the core competencies of CRCs, might be a central competency 
because Management as a large category in this study included a wide range of abilities as shown by its categories. Fourteen content areas of the typical clinical research role provided by the ACRP included 9 management-related areas: management of essential documents, investigative site management, clinical trial management, test article accountability and management, project management, data management, business management skills, and personal/professional management [8]. Project management, data management, original source management and document management, which were categories in the present study, are similar to several content areas described by the ACRP. Although other categories are not similar to the names of other content areas established by the ACRP, management is a comprehensive competency including managing research subjects, research-related personnel, material, time and financial resources. Communication, working as a team, behavior as a medical personnel and IT skill may be basic competencies. The first edition of the Oncology Clinical Trials Nurse Competencies in 2010 [12] mentioned strong verbal and written communication skills, ability to work in teams, oncology nursing experience, and ability to utilize computers and basic computer programs as initial requirements of clinical trial nurses. However, it is not clear whether or not there are differences in the level of competency required for each of the 12 core competencies extracted in this study. Competency of behavior as a medical personnel might be controversial. In our discussion, this competency does not mean that the CRC must have a medical license. However, this result suggests that CRCs need the ability to carry out basic responsibilities as medical personnel such as respecting patients, handling personal medical information, and understanding the contents of medical records. The lack of clear regulations and policies that guide delegation of clinical research activities creates risks to research participants and the quality of clinical research [13]. Further research is needed to clarify the scopes of practice of CRCs who do not have a medical license.

A standard training program for CRCs should consider covering the core competencies of CRCs revealed in this study. However, a well-structured education program for professionals needs to include not only core competencies but also the scope of practice and appropriate performance level as shown by the published report entitled "An Advanced Pharmacy Practice Framework for Australia" [14]. The scope of practice of CRCs was not revealed in the present study, and there are no descriptions in previous studies. Although several core competencies such as rational problem-solving, being knowledgeable, consultation and leadership extracted in this study are similar to the competencies or roles of advanced practice nurses (APNs) [15], the appropriate performance level is not clear from only the elements of core competencies revealed in this study. Further research regarding the scopes of practice of CRCs and performance level from general to advanced practice of CRCs is needed.

This study has several limitations. We extracted core competencies from the presentations given by opinion leaders about what is expected of CRCs. This means that we gathered a wide range of opinions from study participants about what they expected to be the role of CRCs. Therefore, the results of this study might be loose compared to interviews focusing just on core competencies of CRCs, but the validity of these results cannot be denied because we confirmed data saturation.

Regarding the process of data analysis using text mining, the relevancies of the large categories were not analyzed in this study. Other elements or influencing factors might be deduced if the relevancies of the core competencies are analyzed.

In conclusion, this study identified 12 core competencies that CRCs require, which were rational problem-solving, management, coordination, communication, being knowledgeable, caring for research subjects, consultation, ensuring the quality of clinical researches, working as a team, leadership, behavior as a medical personnel and IT skill. This finding suggests that those core competencies are essential abilities of CRCs working in a clinical setting with research subjects. Further research on clarifying the 
scopes of practice and performance level of CRCs is needed in order to develop an education program that focuses on the core competencies of CRCs.

\section{Acknowledgments}

The authors gratefully acknowledge the 13 opinion leaders for participating in this study.

\section{References}

[1] Association of Clinical Research Professional, Available at: http://www.acrpnet.org/ MainMenuCategory/Certification/CRCCertification.aspx. Accessed November 22, 2015.

[2] L. A. Speicher, G. Fromell, S. Avery, D. Brassil, L. Carlson, E. Stevens and M. Toms, "The Critical Need for Academic Health Centers to Assess the Training, Support, and Career Development Requirements of Clinical Research Coordinators: Recommendations from the Clinical and Translational Science Award Research Coordinator Taskforce", Clin. Transl. Sci., vol. 5, no. 6, (2012), pp. 470-475.

[3] S. A. Kwon and N. Y. Yang, "Workload and Work Importance of Clinical Research Nurse", International Journal of Bio-Science and Bio-Technology, vol. 7, no. 5, (2015), pp. 85-92.

[4] J. Ratzan, "Inspections, Compliance, Enforcement, and Criminal Investigations: FDA Warning Letter", Available at: http://www.fda.gov/ICECI/EnforcementActions/WarningLetters/ucm248622.htm. Accessed November 22, 2015.

[5] OECD's Definition and Selection of Competencies (DeSeCo) Project. The Definition and Selection of Key Competencies: The Executive Summary (2005). Available at: http://www.deseco.admin.ch/bfs/deseco/en/index/02.html. Accessed November 22, 2015.

[6] L. Axley, “Competency: A Concept Analysis", Nursing Forum, vol. 43, no. 4, (2008), pp. 214-222.

[7] Oncology Nursing Society. 2016 Oncology Clinical Trials Nurse Competencies. Available at: https://www.ons.org/sites/default/files/OCTN_Competencies_FINAL.PDF Accessed November 27, (2016).

[8] J. Holcomb, "The Professional Development Pathway -Establishing a Standard for Clinical Research Training", Monitor, December, (2011), pp. 78-81.

[9] A. S. Sonstein, J. Seltzer, R. Li, H. Silva, C. T. Jones and E. Daemen, "Moving from Compliance to Competency: A Harmonized Core Competency Framework for the Clinical Research Professional", Clinical Researcher, (2014), pp. 17-23.

[10] D. F. Polit and C. T. Beck, "Nursing Research: Generating and Assessing Evidence for Nursing Practice", Lippincott Williams \& Wilkins, Philadelphia, (2008).

[11] R. Feldman and J. Sanger, "Introduction to Text Mining, In: Feldman R and Sanger J. The Text Mining Handbook; Advanced Approaches in Analyzing Unstructured Data", Cambridge, UK: Cambridge University Press; 2007:1-18. Available at: http://www.roelsbeestenboel.nl/text.pdf. Accessed November $22,2015$.

[12] Oncology Nursing Society. Oncology Clinical Trials Nurse Competencies, Available at: https://www.ons.org/sites/default/files/ctncompetencies.pdf. Accessed November 22, 2015, (2010).

[13] C. T. Jones, C. Hastings and L. L. Wilson, "Research nurse manager perceptions about research activities performed by non-nurse clinical research coordinators", Nurse Outlook vol. 6, no. 3, (2015), pp. 474-483.

[14] The Advanced Pharmacy Practice Framework Steering Committee on behalf the pharmacy profession in Australia, "An Advanced Pharmacy Practice Framework for Australia”, October 2012. Available at: http://advancedpharmacypractice.com.au/download/framework/advanced-pharmacy-practiceframework.pdf. Accessed February 7, 2017.

[15] J. A. Spross, M. T. Lawson and A. B. Hamric, "Conceptualizations of Advanced Practice Nursing, A Definition of Advanced Practice Nursing", Edited Ann B. Hamric, Judith A. Spross, Charlence M. Hanson, Elsevier Saunders, St. Louis, vol. 4, (2014), pp. 67-85. 


\section{Authors}

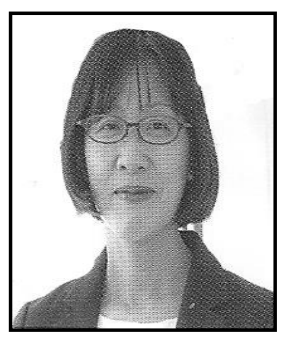

Tochigi Izumi Kohara, RN, DNSc, CCRP. Professor, School of Nursing, Jichi Medical University. 3311-159 Yakushiji, Shimotsuke Tochigi 329-0498, Japan. TEL +81-285-58-7425 FAX +81-285-44-7257. E-mail: ikohara@jichi.ac.jp

1989 The Degree of Bachelor of Science in Nursing from Chiba University. 1994 The Degree of Master of Science in Nursing from University of Kitasato 2009. The Degree of Doctor of Nursing Science from Tokyo Medical and Dental University Year of Experience and Organization 1989 - 1992 Nursing Staff, The Jikei University hospital, Tokyo, 1994 - 1998, Assistant, The Jikei University, School of Nursing, Tokyo, 1998 - 1999 Nursing Staff, National Cancer Center Hospital East, Chiba 1999 - 2009 Clinical Research Coordinator, National Cancer Center Hospital East, Chiba 2009 - 2015, Associate Professor, School of Nursing, Jichi Medical University, Tochigi 2015- Professor, School of Nursing, Jichi Medical University. 